\title{
Structural Parameters Governing Low Temperature Activity of Small Pore Copper Zeolites in $\mathrm{NH}_{3}-\mathrm{SCR}$
}

Authors: Michiel De Prins, ${ }^{a}$ Elke Verheyen, ${ }^{a}$ Andreas Hoffmann, ${ }^{a}$ Gina Vanbutsele, ${ }^{a}$ Sreeprasanth Pulinthanathu Sree, ${ }^{a}$ Stef Kerkhofs, ${ }^{a}$ Leen Van Tendeloo, ${ }^{b}$ Frank-Walter Schütze, ${ }^{c}$ Johan Martens*a

${ }^{a}$ Center for Surface Chemistry and Catalysis: Characterization and Application Team University of Leuven, Leuven, Celestijnenlaan 200 F, 3001 Heverlee, Belgium.

E-mail: johan.martens@kuleuven.be

${ }^{b}$ Umicore, Olen, 2250, Belgium

${ }^{c}$ Umicore Ag\&Co. KG, Hanau, 63456, Germany

Key words: $\mathrm{NH}_{3}$-SCR; zeolite; copper; selective catalytic reduction 


\begin{abstract}
Low temperature performance is key for catalysts used in selective catalytic reduction of $N O_{x}$ with ammonia $\left(\mathrm{NH}_{3}-\mathrm{SCR}\right)$. The best performing $\mathrm{NH}_{3}$-SCR catalysts are based on small pore copper loaded zeolites. A key question remains which structural and compositional parameters make a copper zeolite catalytically active in this application. In this work a collection of 83 different zeolite samples having 25 different frameworks and compositional variations was evaluated to uncover the critical structural and compositional parameters governing catalytic activity at $150{ }^{\circ} \mathrm{C}$. The Si/Al ratio, the content of double six ring building units, the framework density and pore dimensionality were identified as having a strong impact on the catalytic activity of zeolites. A critical value for each of these parameters was determined. This knowledge was used to predict MOZ, SZR and GME as active $\mathrm{NH}_{3}$-SCR catalysts. They were synthesized respecting the compositional prerequisites and their catalytic evaluation confirmed the predicted high catalytic activity.
\end{abstract}

\title{
1. Introduction
}

Selective catalytic reduction of $\mathrm{NO}_{x}$ using ammonia $\left(\mathrm{NH}_{3}-\mathrm{SCR}\right)$ is one of the few technologies for abating $\mathrm{NO}_{\mathrm{x}}$ emissions by diesel engines. In Western Europe $40 \%$ of the new passenger cars and almost all heavy duty transport is powered by a diesel engine[1]. The diesel engine is recognized as one of the power sources for vehicles with the lowest $\mathrm{CO}_{2}$ emission, sometimes even outperforming the electric vehicle, especially in the SUV and heavy duty categories. The downside of diesel vehicles is the emission of particulate matter, $\mathrm{CO}$, unburnt hydrocarbons and $\mathrm{NO}_{\mathrm{x}}$. The emission regulations for these air pollutants are increasingly stringent, pushing the performance of exhaust gas cleaning technologies to the limits. In view of this evolution, there is a constant need for new, more active catalysts, adsorbents and filters. $\mathrm{NH}_{3}-\mathrm{SCR}$ is one of the few technologies for abating $\mathrm{NO}_{\mathrm{x}}$ emissions from diesel engines. Given the dynamic nature of the exhaust gas properties, the $\mathrm{NH}_{3}$-SCR catalyst needs to be active in a wide temperature window and be able to withstand hydrothermal conditions exceeding $700{ }^{\circ} \mathrm{C}$ upon diesel particulate filter regeneration. In addition to high activity and selectivity, a high hydrothermal stability of the catalyst is therefore required. Zeolites loaded with transition metals such as $\mathrm{Fe}$ or $\mathrm{Cu}$ are ideal candidates for this task. Of these two, copper zeolites perform better in the low temperature regime typical of diesel exhaust in driving cycles of emission standards[2,3]. The first notion of zeolites for $\mathrm{NH}_{3}$-SCR already dates back to 1986 when Cu-loaded ZSM-5 zeolite was first mentioned[4]. This medium pore zeolite with framework type MFI, was the first used in the field of $\mathrm{NH}_{3}$-SCR, followed by BEA zeolite[5] and FAU zeolite[6], both being large pore zeolites. Since the introduction of CHAbased zeolite catalysts in the field, attention has largely shifted towards the use of small pore zeolites. These have some advantages over their larger pore counterparts such as a higher hydrothermal stability and often a higher selectivity [3,7]. The limited pore diameter is another advantage of small pore zeolites since it limits the adsorption of hydrocarbons, which could ignite under high temperature conditions leading to thermal damage to the zeolite. The introduction of the copper loaded CHA zeolite triggered a more general interest in small pore aluminosilicate zeolite types such as AEI and AFX[3,8]It led to a quest for hydrothermally robust zeolites withstanding hydrothermal aging up to $900{ }^{\circ} \mathrm{C}$, a property of among others the BIK type zeolite[9]. At this moment, the key zeolite features needed for the high catalytic activity and hydrothermal stability are highly debated topics. It has been shown that alkali and earth alkaline cations ion exchanged into the zeolite can play a role in the activity and hydrothermal stability of a zeolite catalyst in $\mathrm{NH}_{3}$-SCR $[9,10]$. The location of $\mathrm{Cu}^{2+}$ ions in the pores of zeolite catalysts, the copper speciation and formation of dimers and clusters is intensively investigated. This has led to the discovery of preferential sites for $\mathrm{Cu}^{2+}$ ions, which differ for different topologies[11]. The $\mathrm{Cu}^{2+}$ ions are often located in the double six ring (d6r) of oxide tetrahedra. These are typical building 
units of small pore zeolites with high activity in $\mathrm{NH}_{3}$-SCR, such as those with $\mathrm{CHA}$ [12] and AEI[13] framework types, but also the large pore zeolite FAU[14,15]. Most publications treat the activity of zeolite samples with one framework type in particular, or a small number of zeolites with different framework types and/or chemical composition. Recently Wang et al. reported a comparative study of 9 different topologies and concluded that cage-type frameworks have better $\mathrm{NH}_{3}$-SCR performance than straight-channel or hybrid pore structures[16]. Review articles sometimes combine multiple frameworks for comparison [17].

In this work we created an unprecedented large dataset on catalytic performance in $\mathrm{NH}_{3}-\mathrm{SCR}$. Most synthetic small pore zeolites with aluminosilicate composition mentioned in the Atlas of Zeolite Framework Types withstanding ion exchanges with ammonium and copper ions and thermal treatment at $450^{\circ} \mathrm{C}$ are included. Statistical analysis of the data enabled us to gain insights in the relationships of structure, composition and catalytic performance for $\mathrm{Cu}$-exchanged small-pore zeolites for $\mathrm{NH}_{3}-\mathrm{SCR}$. This insight led to the identification of three overlooked zeolite types. These were synthesized and catalytically evaluated to validate the predictions.

\section{Materials and Methods}

\subsection{Zeolite samples}

25 zeolite topologies were synthesized according to literature recipes (Figure S1). An overview of these zeolite samples with specification of the origin, information on templates used in the synthesis and the chemical composition is provided in Table S1. Some samples with the same framework type were synthesized using different recipes, resulting in different compositions. They are distinguished by a number between brackets. Besides these zeolites composing the library for the statistical analysis, three additional zeolite types were synthesized. The details of the MOZ, SZR and GME syntheses are given below.

MOZ zeolite was synthesized as ZSM-10, described in example 2 of patent EP3363540[18]. A gel with molar ratios of $14.7 \mathrm{SiO}_{2}: \mathrm{Al}_{2} \mathrm{O}_{3}: 0.85 \mathrm{R}: 6.15 \mathrm{~K}_{2} \mathrm{O}: 450 \mathrm{H}_{2} \mathrm{O}$ in which $\mathrm{R}$ represents 1,4-dimethyl1,4-diazabicyclo[2.2.2] octane diiodide was prepared as follows: $8.8 \mathrm{~g}$ Cab-O-Sil M5 was added to a mixture of $4.93 \mathrm{~g} \mathrm{KOH} \mathrm{(VWR)} \mathrm{and} 48.4 \mathrm{~mL} \mathrm{H}_{2} \mathrm{O}$ and left stirring for $3.5 \mathrm{~h}$ in a closed polypropylene bottle. To a second solution of $1.98 \mathrm{~g} \mathrm{KOH}$ in $15.4 \mathrm{~mL} \mathrm{H}_{2} \mathrm{O}, 0.54 \mathrm{~g}$ aluminum powder (UCB) was added and stirred in a closed bottle for $3.5 \mathrm{~h}$ before adding $3.35 \mathrm{~g}$ 1,4-dimethyl-1,4diazabicyclo[2.2.2] octane diiodide and stirring for an additional 30 minutes. Both solutions were mixed and stirred for 30 minutes. The resulting synthesis gel was aged at room temperature for 3 days before transferring it to a stainless steel autoclave. The autoclave was introduced in a hot air oven at room temperature and was heated at $1{ }^{\circ} \mathrm{C} / \mathrm{min}$ to $110^{\circ} \mathrm{C}$. The autoclave was kept at this temperature for 13 days without agitation. Afterwards, the solids were recovered by filtration. The powder was washed with water until reaching a neutral $\mathrm{pH}$ in the percolating water. It was dried overnight at $60{ }^{\circ} \mathrm{C}$. The obtained powder was calcined for $8 \mathrm{~h}$ at $550{ }^{\circ} \mathrm{C}$ in a muffle furnace heated from room temperature at $1{ }^{\circ} \mathrm{C} / \mathrm{min}$.

The SZR zeolite synthesis was performed according to a SUZ-4 recipe as described in method $\mathrm{C}$ in a publication by Asensi et al.[19] The synthesis gel with molar ratios of $21.1 \mathrm{SiO}_{2}-1 \mathrm{Al}_{2} \mathrm{O}_{3}-2.6 \mathrm{R}-3.9$ $\mathrm{K}_{2} \mathrm{O}-496.6 \mathrm{H}_{2} \mathrm{O}$ was prepared as follows: $5.30 \mathrm{~g}$ TEAOH (40\% aq Alfa) was mixed with $17.64 \mathrm{~g}$ Ludox AS-40. A mixture of $35.99 \mathrm{~g} \mathrm{H}_{2} \mathrm{O}$ with $2.46 \mathrm{~g} \mathrm{KOH}$ (pellets, p.a. Acros) and $0.30 \mathrm{~g}$ Al-powder (UCB) was added slowly while stirring. The resulting mixture was stirred further until homogenization 
and then transferred to a Teflon lined autoclave, which was then placed in a preheated oven at $150{ }^{\circ} \mathrm{C}$ for 7 days while tumbling. Filtration and calcination were performed as for the MOZ zeolite

GME zeolite was synthesized using N,N-dimethyl,3,5-dimethylpiperidinium hydroxide template documented for synthesizing MER zeolite[20], but used in a procedure for preparing AEI zeolite[21]. The synthesis gel had following molar proportions: 78.4 $\mathrm{SiO}_{2}-1 \mathrm{Al}_{2} \mathrm{O}_{3}-12.0 \mathrm{R}-21.8 \mathrm{Na}_{2} \mathrm{O}-1075.0$ $\mathrm{H}_{2} \mathrm{O}$, in which $\mathrm{R}$ represents $\mathrm{N}, \mathrm{N}$-dimethyl,3,5-dimethylpiperidinium hydroxide. To obtain the synthesis gel, $0.23 \mathrm{~g} \mathrm{NaOH}$ pellets (Fisher Scientific) were dissolved in $38.54 \mathrm{~g} \mathrm{~N}, \mathrm{~N}$-dimethyl,3,5dimethylpiperidinium hydroxide (20.46 wt $\%$ in $\mathrm{H}_{2} \mathrm{O}$, Sachem). To this mixture $59.20 \mathrm{~g}$ sodium silicate (Merck) was gradually added while stirring. Finally $2.02 \mathrm{~g} \mathrm{CBV-500} \mathrm{(Zeolyst)} \mathrm{was} \mathrm{added} \mathrm{and} \mathrm{the}$ mixture was stirred until homogenization. The obtained gel was transferred to a stainless steel autoclave and introduced in a preheated oven at $135{ }^{\circ} \mathrm{C}$. No agitation was applied. After 7 days, the autoclave was removed from the oven. Filtering was performed as for the MOZ zeolite. GME was calcined for 8 hours at $600{ }^{\circ} \mathrm{C}$, heating up at $1{ }^{\circ} \mathrm{C} / \mathrm{min}$.

\subsection{Preparation of catalysts}

The alkali and earth alkaline cations were removed by subjecting all zeolite powders to an exchange with ammonium ions. For this, the zeolite powder was suspended in a boiling $0.5 \mathrm{M} \mathrm{NH}_{4} \mathrm{Cl}$ solution (100 mL solution for $1 \mathrm{~g}$ of zeolite) and stirred under reflux conditions for $4 \mathrm{~h}$. The ammonium exchanged zeolite was recovered by centrifugation and subsequently washed with water. The samples were dried at $60^{\circ} \mathrm{C}$ overnight.

Ammonium exchanged zeolites were exchanged with cupric ions by adding $2 \mathrm{~g} \mathrm{NH}_{4}$-exchanged zeolite to a $200 \mathrm{~mL}$ aqueous solution containing $0.0189 \mathrm{~g}$ copper acetate monohydrate (Chem-Lab, 99+\%). This suspension was stirred in a closed container for $20 \mathrm{~h}$ at room temperature. The zeolite was recovered by centrifugation and washing. If needed, this procedure was repeated up to 3 times. Zeolites with a Si/Al lower than about 6 generally received two copper loadings as they are more likely to take up copper from solution. Zeolites with a high $\mathrm{Si} / \mathrm{Al}$ generally received three copper exchanges. This was done to obtain comparable copper loadings in all samples. $\mathrm{A} \mathrm{Cu} / \mathrm{Al}$ ratio of 0.5 or lower was targeted to allow for charge compensation of divalent $\mathrm{Cu}^{2+}$ with zeolite framework charges generated by framework $\mathrm{Al}$ atoms. Afterwards, the ion exchanged zeolite powder was dried at $60^{\circ} \mathrm{C}$ overnight.

The zeolite powder was pressed between two stainless steel blocks at a pressure of $30 \mathrm{MPa}$ to obtain flakes, which were crushed and sieved to obtain pellets sized $125-250 \mu \mathrm{m}$. These were loaded in the reactor for evaluating catalytic activity in $\mathrm{NH}_{3}-\mathrm{SCR}$ (section 2.4).

\subsection{Physico-chemical characterization of zeolite samples}

The crystallinity and phase purity of the investigated zeolites was verified with X-ray diffraction patterns recorded on a STOE STADI P Combi diffractometer. This equipment has a focusing Ge(111) monochromator $(\mathrm{CuK} \alpha$ radiation, $\lambda=0.154 \mathrm{~nm})$ with high throughput setup in transmission geometry, an image plate position sensitive detector (IP-PSD), an internal resolution of $0.03^{\circ}$ and a scan-rate of $1000 \mathrm{~s}$.

The $\mathrm{Si}, \mathrm{Al}$ and $\mathrm{Cu}$ content of the zeolite samples were determined on an axial simultaneous ICP-OES instrument (Varian 720-ES) with cooled cone interface and oxygen free optics. To this aim the zeolites were either dissolved via a chemical dissolution with HF to determine cation contents or via a thermal 
route to determine $\mathrm{Si}$ and $\mathrm{Al}$ content. In the chemical dissolution route $50 \mathrm{mg}$ of zeolite sample was dissolved in a mixture of $0.5 \mathrm{~mL}$ aqua regia $\left(1: 3 \mathrm{HNO}_{3}: \mathrm{HCl}\right.$ from respectively Sigma Aldrich, for analysis $65 \%$ and Fischer Scientific, 37\%) and $3 \mathrm{~mL} \mathrm{HF} \mathrm{(40 \%} \mathrm{ChemLab)} \mathrm{in} \mathrm{a} \mathrm{Teflon} \mathrm{beaker.} \mathrm{This}$ beaker was heated for $1 \mathrm{~h}$ at $110{ }^{\circ} \mathrm{C}$. Once cool, $10 \mathrm{~mL}$ deionized water and $2.8 \mathrm{~g} \mathrm{H}_{3} \mathrm{BO}_{3}$ (Acros Organics $99.99 \%$ trace metal basis) were added to neutralize the excess HF. The thermal route started from $100 \mathrm{mg}$ zeolite sample, mixed with $500 \mathrm{mg} \mathrm{LiBO}_{2}$ (Aldrich) in a graphite crucible. This was placed in an oven set at $1000{ }^{\circ} \mathrm{C}$ for $15 \mathrm{~min}$, causing the solid mixture to melt. Upon removal from the oven, the obtained liquid droplet was immediately dissolved in $50 \mathrm{~mL} 0.42 \mathrm{~N} \mathrm{HNO}_{3}$ (Sigma Aldrich for analysis $65 \%$ ) in a Teflon beaker while stirring. Small quantities of graphite that were also transferred this way were precipitated by leaving the sample stationary overnight. The samples obtained via either the chemical or thermal dissolution route were introduced into the ICP instrument via a Varian SPS3 Sample Preparation System. The residual alkali and alkaline earth metal content (K, Na, Cs, $\mathrm{Sr}, \ldots$ ) was determined via atomic absorption spectroscopy (Varian SpectrAA 20 Plus).

High-Resolution Scanning Electron Microscopy (HRSEM) images were obtained with a Nova NanoSEM450 (FEI, Hillsboro, OR). Samples were mounted on aluminum stubs by drying a droplet of a zeolite dispersed in acetone on the stub. They were observed without any further modification enabled by the use of low electron accelerating voltages of $500 \mathrm{~V}$ to $2 \mathrm{kV}$.

\subsection{Evaluation of catalytic activity in $\mathrm{NH}_{3}-\mathrm{SCR}$}

Catalyst pellets were loaded in a quartz fixed bed tubular continuous flow reactor with online reaction product analysis. $\mathrm{NO}, \mathrm{NO}_{2}, \mathrm{SO}_{2}$ and $\mathrm{NH}_{3}$ concentrations were analyzed simultaneously on an $\mathrm{ABB}$ AO2020-Limas11HW UV photometer. $\mathrm{CO}, \mathrm{N}_{2} \mathrm{O}$ and $\mathrm{CO}_{2}$ were analyzed in parallel on an $\mathrm{ABB}$ AO2020-URAS26 NDIR photometer.

Prior to the activity test, the catalyst underwent a pretreatment in a gas flow of $5 \% \mathrm{O}_{2}$ in $\mathrm{N}_{2}$ at $450{ }^{\circ} \mathrm{C}$, the highest test temperature. The ramp rate was set to be $5^{\circ} \mathrm{C} / \mathrm{min}$. After the pretreatment, the catalyst temperature was decreased to $150{ }^{\circ} \mathrm{C}$. A gas mixture consisting of $500 \mathrm{ppm} \mathrm{NO}, 450 \mathrm{ppm} \mathrm{NH}, 5 \% \mathrm{O}_{2}$, $2 \% \mathrm{CO}_{2}, 2.2 \% \mathrm{H}_{2} \mathrm{O}$ was used for $\mathrm{NH}_{3}$-SCR performance evaluation. $\mathrm{N}_{2}$ served as a balancing gas. The gas hourly space velocity (GHSV) was fixed at $30,000 \mathrm{~h}^{-1}$, obtained by a gas flow rate of $250 \mathrm{~mL} / \mathrm{min}$ over a $0.5 \mathrm{~cm}^{3}$ catalyst bed. The volume of the bed was determined at the start of the experiment and corresponds to ca. $0.225 \mathrm{~g}$ catalyst, depending on the sample. The volume can evolve during the test. The $\mathrm{NO}_{\mathrm{x}}$ conversion was calculated from the difference between $\mathrm{NO}_{\mathrm{x}}$ concentrations at the reactor inlet (in) and the reactor outlet (out):

$$
N O_{x} \text { conversion }(\%)=\frac{\left[N O_{i n}\right]-\left[N O_{x \text { out }}\right]}{\left[N O_{i n}\right]}
$$

In which $\left[\mathrm{NO}_{\mathrm{x}}\right]$ is the sum of the $\mathrm{NO}$ and $\mathrm{NO}_{2}$ concentrations expressed in ppm. As only $\mathrm{NO}$ is in the feed gas, $\left[\mathrm{NO}_{\mathrm{x}}\right.$ in] is simplified to $\left[\mathrm{NO}_{\text {in }}\right]$. The $\mathrm{N}_{2}$ concentration in the reaction products was not analyzed. $\mathrm{NO}_{\mathrm{x}}$ that was converted was considered to be $\mathrm{N}_{2}$ and $\mathrm{N}_{2} \mathrm{O} . \mathrm{N}_{2} \mathrm{O}$ is a molecule with a very high global warming potential of 298 times that of $\mathrm{CO}_{2}$. It's formation was monitored separately

The composition of the feed gas with $500 \mathrm{ppm} \mathrm{NO}$ and $450 \mathrm{ppm} \mathrm{NH} \mathrm{N}_{3}$ was selected such that the $\mathrm{NO}_{\mathrm{x}}$ conversion theoretically was limited to $90 \%$ provided the reaction proceeds via the standard $\mathrm{NH}_{3}-\mathrm{SCR}$ reaction (eqn. 1) or the fast $\mathrm{NH}_{3}-\mathrm{SCR}$ reaction (eqn. 2):

$$
\begin{aligned}
& 4 \mathrm{NO}+4 \mathrm{NH}_{3}+\mathrm{O}_{2} \rightarrow 4 \mathrm{~N}_{2}+6 \mathrm{H}_{2} \mathrm{O} \\
& \mathrm{NO}+\mathrm{NO}_{2}+2 \mathrm{NH}_{3} \rightarrow 2 \mathrm{~N}_{2}+3 \mathrm{H}_{2} \mathrm{O}
\end{aligned}
$$


In addition to the $\mathrm{NO}_{\mathrm{x}}$ conversion, the turn over frequency (TOF) was calculated as:

$$
\operatorname{TOF}\left(\mathrm{s}^{-1}\right)=\frac{\text { NO conversion rate }\left(\frac{\mathrm{mol}}{\mathrm{S}}\right)}{\text { Cu atom content }(\mathrm{mol})}
$$

The temperature was stepwise increased from 150 to $450{ }^{\circ} \mathrm{C}$ with fixed temperature ramps and $50{ }^{\circ} \mathrm{C}$ intervals. Isothermal periods were respected before reaction product sampling at each temperature plateau (Table 1). At $150{ }^{\circ} \mathrm{C}$ and $175^{\circ} \mathrm{C}$ it takes longer to reach a stable reaction product composition than at higher temperatures. Therefore, the reactor was allowed to stabilize for 120 and 90 minutes, respectively, before product sampling. At these low temperatures, phenomena such as ammonia adsorption or desorption [22] and ammonium nitrate formation [23-25] take place. The kinetic data pertain to the steady state where the ammonia adsorption reached equilibrium. At a reaction temperature of $150{ }^{\circ} \mathrm{C}$, under the investigated reaction conditions, no catalyst reached $100 \% \mathrm{NO}_{\mathrm{x}}$ conversion. There was no shortage of ammonia to carry out the reaction. On the most active zeolite catalysts, the conversion of $\mathrm{NO}_{\mathrm{x}}$ molecules to $\mathrm{NH}_{3}$ at $150{ }^{\circ} \mathrm{C}$ was close to a $1 / 1$ ratio, indicating that all $\mathrm{NH}_{3}$ is being used for $\mathrm{NO}_{\mathrm{x}}$ conversion according to the standard SCR reaction. For less active materials, the conversion ratio of $\mathrm{NO}_{x}$ to $\mathrm{NH}_{3}$ was either lower or higher. In those catalysts, other types of SCR reactions or adsorption phenomena may be still ongoing after $2 \mathrm{~h}$ on stream. A return to $150{ }^{\circ} \mathrm{C}$, after the highest investigated reaction temperature of $450{ }^{\circ} \mathrm{C}$, enabled detection of degradation of catalytic performance during the testing, if any.

Table 1: Temperatures and stabilization times in $\mathrm{NH}_{3}$-SCR catalytic evaluation.

\begin{tabular}{|c|c|}
\hline Temperature $\left({ }^{\circ} \mathbf{C}\right)$ & Time to stabilize (min) \\
\hline 150 & 120 \\
\hline 175 & 90 \\
\hline 200 & 70 \\
\hline 250 & 70 \\
\hline 300 & 70 \\
\hline 350 & 70 \\
\hline 400 & 70 \\
\hline 450 & 70 \\
\hline 150 & 70 \\
\hline
\end{tabular}

The hydrothermal stability of the promising new zeolite types was evaluated by heating pellets of the material with a diameter of $125-250 \mu \mathrm{m}$ at $5{ }^{\circ} \mathrm{C} / \mathrm{min}$ to $750{ }^{\circ} \mathrm{C}$ in a quartz tube under a $2 \mathrm{~mL} / \mathrm{min}$ air flow with an absolute humidity of $12 \mathrm{vol} \%$ for $3 \mathrm{~h}$. Cooling was performed under a $40 \mathrm{~mL} / \mathrm{min}$ dry nitrogen flow. 


\section{Results and discussion}

\section{1. $\mathrm{NH}_{3}-\mathrm{SCR}$ performance test validation}

The $\mathrm{NH}_{3}-\mathrm{SCR}$ activity of the zeolites was estimated from the $\mathrm{NO}_{\mathrm{x}}$ conversion reached at the end of each temperature plateau (Table 1). Full curves of $\mathrm{NO}_{\mathrm{x}}$ conversion by temperature are presented in Figure S2. The more active catalysts reached $\mathrm{NO}_{x}$ conversion levels exceeding $90 \%$ at $175{ }^{\circ} \mathrm{C}$ and higher, sometimes up to $300{ }^{\circ} \mathrm{C}$. This excess $\mathrm{NO}_{\mathrm{x}}$ conversion was due to ammonia storage on the acid sites of the zeolite. The catalytic activity of the Cu-zeolite materials from the library varied widely. To illustrate this, the catalytic activity of four catalysts with very different performance is displayed in Figure 1. Of these, $\mathrm{CHA}(1)$ with limited $\mathrm{NO}_{\mathrm{x}}$ conversion lost its crystallinity during the testing protocol.

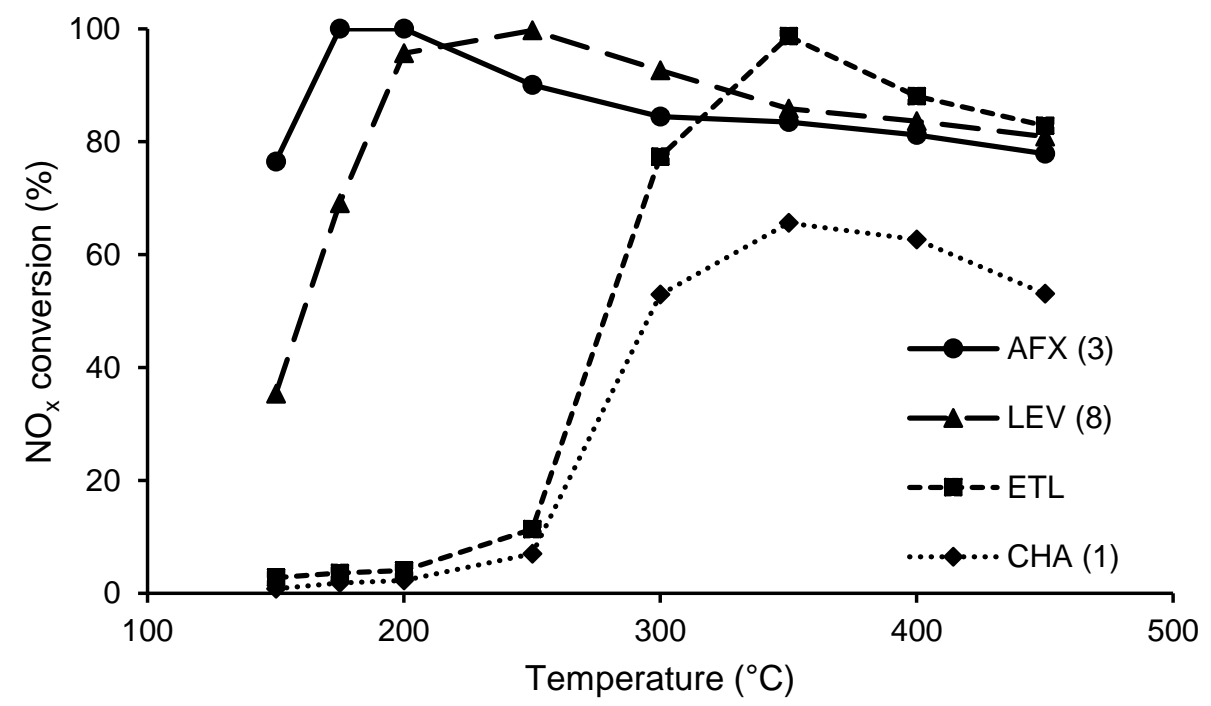

Figure 1: Catalytic activity in the $\mathrm{NH}_{3}$-SCR reaction of a sample with high (AFX), medium (LEV) and low (ETL) NO $O_{x}$ conversion. CHA(1) lost its XRD crystallinity during the reaction protocol.

AFX (3) was among the most active catalysts. The $\mathrm{NO}_{\mathrm{x}}$ conversion over this catalysts reached ca. $75 \%$ at $150{ }^{\circ} \mathrm{C}$. At $175^{\circ} \mathrm{C}$ and $200{ }^{\circ} \mathrm{C}$ it used adsorbed $\mathrm{NH}_{3}$ to go past the theoretical maximum of $90 \% \mathrm{NO}_{\mathrm{x}}$ conversion to reach $100 \%$. At higher temperatures less $\mathrm{NO}_{\mathrm{x}}$ was converted in favor of unwanted side reactions. LEV (8) was less active at low temperature, with a $\mathrm{NO}_{\mathrm{x}}$ conversion of $35 \%$ at $150{ }^{\circ} \mathrm{C}$ and ETL showed almost no $\mathrm{NO}_{\mathrm{x}}$ conversion in the $150-250{ }^{\circ} \mathrm{C}$ range. According to XRD (Figure S3), the ETL zeolite remained crystalline during pretreatment and catalytic evaluation, but ETL zeolites are difficult to load with copper. After three copper exchanges, the copper loading amounted to $1.0 \mathrm{wt} \%$ $\mathrm{Cu}$, corresponding to a $\mathrm{Cu} / \mathrm{Al}$ atomic ratio of 0.03 . Although the copper loading can theoretically still be increased, this loading is sufficient to conclude that ETL is probably not a promising $\mathrm{NH}_{3}-\mathrm{SCR}$ catalyst. Finally, CHA zeolites are among the most active $\mathrm{NH}_{3}$-SCR catalysts reported in literature[2628 ] and active CHA catalysts were included in the collection (Figure S2). In Figure 1, the $\mathrm{NO}_{\mathrm{x}}$ conversion obtained on a particularly poor CHA (1) sample is presented. The framework of this zeolite sample with low $\mathrm{Si} / \mathrm{Al}$ ratio of 2.0 did not remain intact throughout the test according to XRD. This amorphous sample, although containing a high amount of $\mathrm{Cu}(5.7 \mathrm{wt} \%)$, showed little catalytic activity at temperatures below $300{ }^{\circ} \mathrm{C}$, as expected. The $\mathrm{NO}_{\mathrm{x}}$ conversion at higher temperatures remained below $60 \%$. These examples show that the catalyst screening protocol was sensitive enough to discriminate among the zeolites. The $\mathrm{NO}_{\mathrm{x}}$ conversion at $150{ }^{\circ} \mathrm{C}$ was in the range $2-80 \%$ for all zeolites (Figure $\mathrm{S} 2$ ). This corresponds to TOFs with an order of magnitude between $10^{-4} \mathrm{~s}^{-1}$ and $10^{-3} \mathrm{~s}^{-1}$ and is in line with 
what has been reported by others[29,30]. At $175^{\circ} \mathrm{C}$, the most active catalysts already displayed $\mathrm{NO}_{\mathrm{x}}$ conversions close to $100 \%$, making it difficult to differentiate between them.

The 83 catalysts are listed by decreasing $\mathrm{NO}_{\mathrm{x}}$ conversion at $150{ }^{\circ} \mathrm{C}$ in Figure 2 . No immediate trends appear; for instance, the CHA zeolites CHA(1) to (5) are spread all over the ranking.

The structural parameters used in the dataset in this paper were inspired by the datasheets on the Atlas of Zeolite Framework Types, on the International Zeolite Association website[31]. Some of the considered parameters can be intuitively excluded from having an influence on performance, but they were included to make sure the dataset is as complete as possible:

- Framework density (T atoms / $\left.1000 \AA^{3}\right)$

- Unit cell volume $\left(\AA^{3}\right)$

- Accessible volume $(\%)$

- Maximum possible diameter of sphere included (̊)

- Maximum possible diameter of a sphere that can diffuse along in any direction $(\AA)$

- Maximum possible diameter of a sphere that can diffuse along in direction a $(\AA)$

- Maximum possible diameter of a sphere that can diffuse along in direction $b(\AA)$

- Maximum possible diameter of a sphere that can diffuse along in direction c $(\AA)$

- Pore dimensionality

- Presence 5 rings ( 1 or 0 criterion)

- Presence 6-rings (1 or 0 criterion)

- $\%$ of T-atoms in a 6-ring (\%)

- $\%$ of T-atoms in a double 6-ring $(\%)$

- $\%$ of T-atoms in a single 6-ring $(\%)$

The $\%$ of T-atoms in a (double/single) 6-ring was calculated as the probability a random T-atom is in the respective building unit. If T-atoms are part of more than one of these building units, they were counted multiple times.

The zeolite collection comprised one intergrowth: ERI/OFF, also known as zeolite T. Intergrowths were considered to have a combination of the characteristics of both zeolites. ERI and OFF have a different pore size. ERI is a small pore zeolite and OFF is a large pore zeolite. For the pore size, the largest value was considered. Other parameters are quite similar, like the framework density, which is 15.1 and 15.09 $\mathrm{T}$ atoms per $\mathrm{nm}^{3}$ for ERI and OFF respectively. The average value was considered.

The compositional variables were determined via chemical analysis with ICP, AAS, TGA or a combination:

- Concentration of T-atoms (wt $\%$ and $\mathrm{mol} / 100 \mathrm{~g}$ )

$$
\text { ○ } \mathrm{Si}, \mathrm{Al}
$$

- Concentration of copper oxide (wt \%)

- Concentration of alkali and alkaline earth metals (wt\% and mol/100g)

$$
\text { ○ } \mathrm{K}, \mathrm{Na}, \mathrm{Sr}, \mathrm{Cs}
$$

- Molar ratios of main elements

○ $\mathrm{X} / \mathrm{Al}(\mathrm{X}=$ alkali metal and alkaline earth metal cations), $\mathrm{Si} / \mathrm{Al}, \mathrm{Cu} / \mathrm{Al}, \mathrm{Al} /(\mathrm{Si}+\mathrm{Al})$

- Water content of the catalyst after equilibration at room temperature in air with $75 \%$ relative humidity $(\%)$ 


\subsection{Catalytic performance driving parameters}

The structural stability was found to be problematic for zeolites with low Si/Al ratio. Aluminum-rich zeolites are generally known to have limited hydrothermal stability, especially in their acid form[32]. In the zeolite collection, five zeolites lost their crystallinity during the kinetic evaluation. In the sample notation the $\mathrm{Si} / \mathrm{Al}$ atomic ratio is shown between square brackets: EDI [1.0], $\mathrm{ABW}$ (1) [1.0] and ABW (2) [2.4], CHA (1) [2.0], MER (1) [3.9] and MER (2) [2.1]. MER(3) [4.3] was stable and active in $\mathrm{NH}_{3}$ $\mathrm{SCR}$ (Figure $\mathrm{S} 2$ ). For some zeolites the $\mathrm{Si} / \mathrm{Al}$ can be increased via alterations to the synthesis. There are, however, zeolites such as EDI and ABW for which there are currently no known synthesis routes that result in higher Si/Al [33-35]. Though aluminum weakens the zeolite framework, it is vital for the ion exchange capacity. Zeolite frameworks rich in aluminum have more acid sites and can therefore store more $\mathrm{NH}_{3}$, which can benefit their performance. They are also capable of taking up more copper, therefore potentially converting more $\mathrm{NO}_{\mathrm{x}}$. A best compromise of $\mathrm{Si} / \mathrm{Al}$ ratio therefore needs to be found. DDR (1) [35.4] and CDO [31.5] have the highest $\mathrm{Si} / \mathrm{Al}$ in the collection. CDO loaded in three steps reached $1.6 \mathrm{wt} \% \mathrm{Cu}$, which corresponds to a $\mathrm{Cu} / \mathrm{Al}$ of 0.57 . This means that not all $\mathrm{Cu}$ can be present as $\mathrm{Cu}^{2+}$ charge compensating cations. $\mathrm{CDO}$ reached only $15 \% \mathrm{NO}_{\mathrm{x}}$ conversion at $150{ }^{\circ} \mathrm{C}$. DDR (1) also received a three step $\mathrm{Cu}$ ion exchange, resulting in a $\mathrm{Cu}$ loading of $0.6 \mathrm{wt} \%$, or a $\mathrm{Cu} / \mathrm{Al}$ ratio of 0.19 . Stability tests indicated that this DDR sample managed to remain crystalline throughout a $3 \mathrm{~h}$ hydrothermal treatment at $850{ }^{\circ} \mathrm{C}$. In contrast, $\mathrm{CDO}$, despite its high $\mathrm{Si} / \mathrm{Al}$, did not survive a hydrothermal treatment up to $750{ }^{\circ} \mathrm{C}$. Apart from $\mathrm{Si} / \mathrm{Al}$ ratio, framework, cations and crystal size and morphology are expected to play a role in the hydrothermal stability of a zeolite. Additional synthesis efforts were made on the DDR framework to lower the Si/Al ratio. This eventually resulted in DDR (3) [14.7]. After a three step $\mathrm{Cu}$ ion exchange, a loading of $1.3 \mathrm{wt} \% \mathrm{Cu}$ was obtained for this material, corresponding to a $\mathrm{Cu} / \mathrm{Al}$ atomic ratio of 0.2 . $\mathrm{Cu}$ loading remained problematic for DDR, despite lowering the Si/Al. DDR had poor catalytic performance.

When the zeolite samples are ranked in the order of increasing $\mathrm{Si} / \mathrm{Al}$ ratio, the first zeolite to remain stable through the test protocol is LTL with Si/Al ratio of 3.2. All zeolites, except MER (1), of the collection with still higher $\mathrm{Si} / \mathrm{Al}$ ratio are stable. Therefore, a $\mathrm{Si} / \mathrm{Al}$ ratio of at least 3.2 is considered an essential compositional criterion for retaining a candidate zeolite for $\mathrm{NH}_{3}-\mathrm{SCR}$ catalysis. 


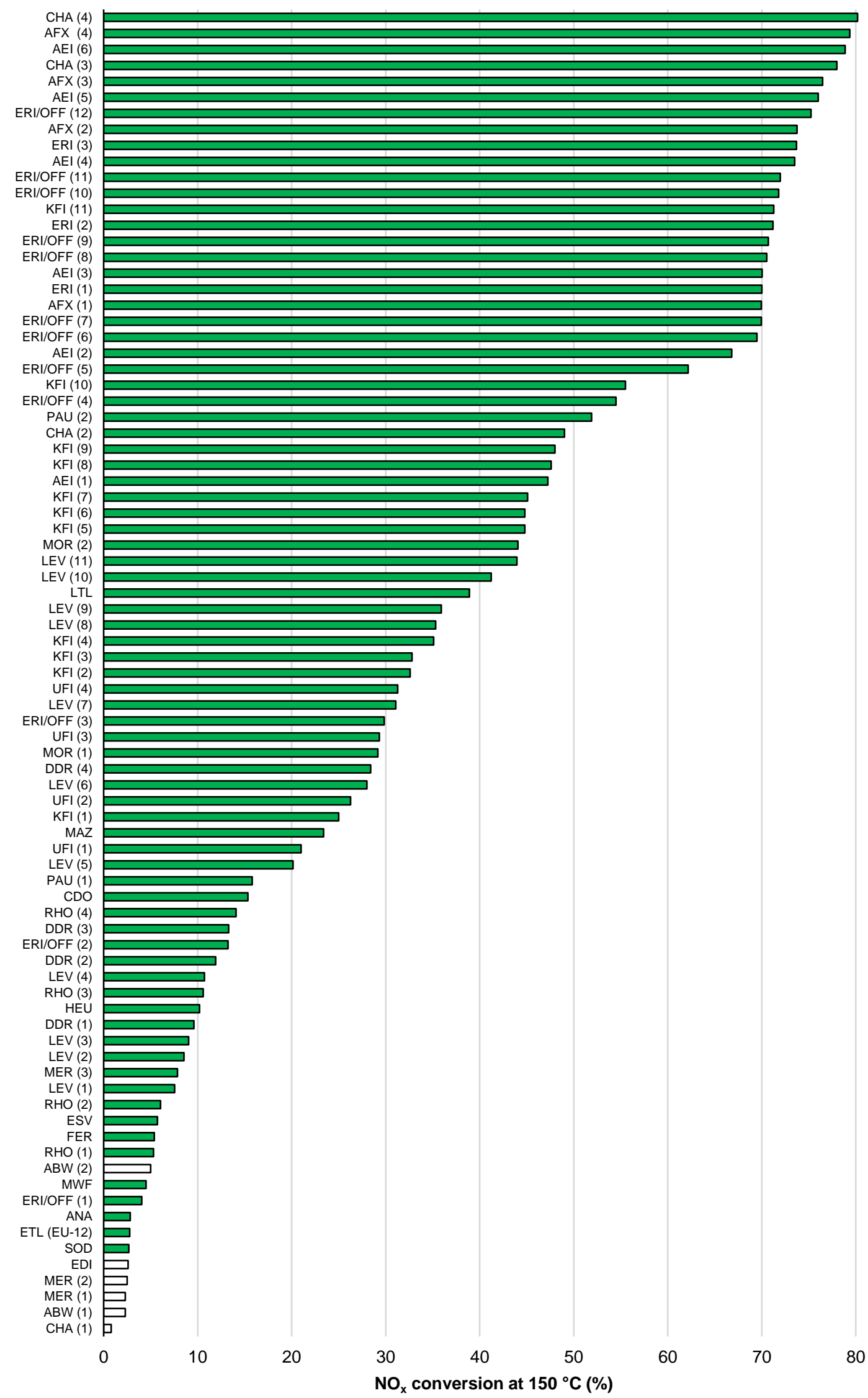

Figure 2: $\mathrm{NO}_{x}$ conversion at $150^{\circ} \mathrm{C}$ on the copper zeolite samples. The zeolite catalysts that remain stable during catalytic testing according to XRD are highlighted in green. 


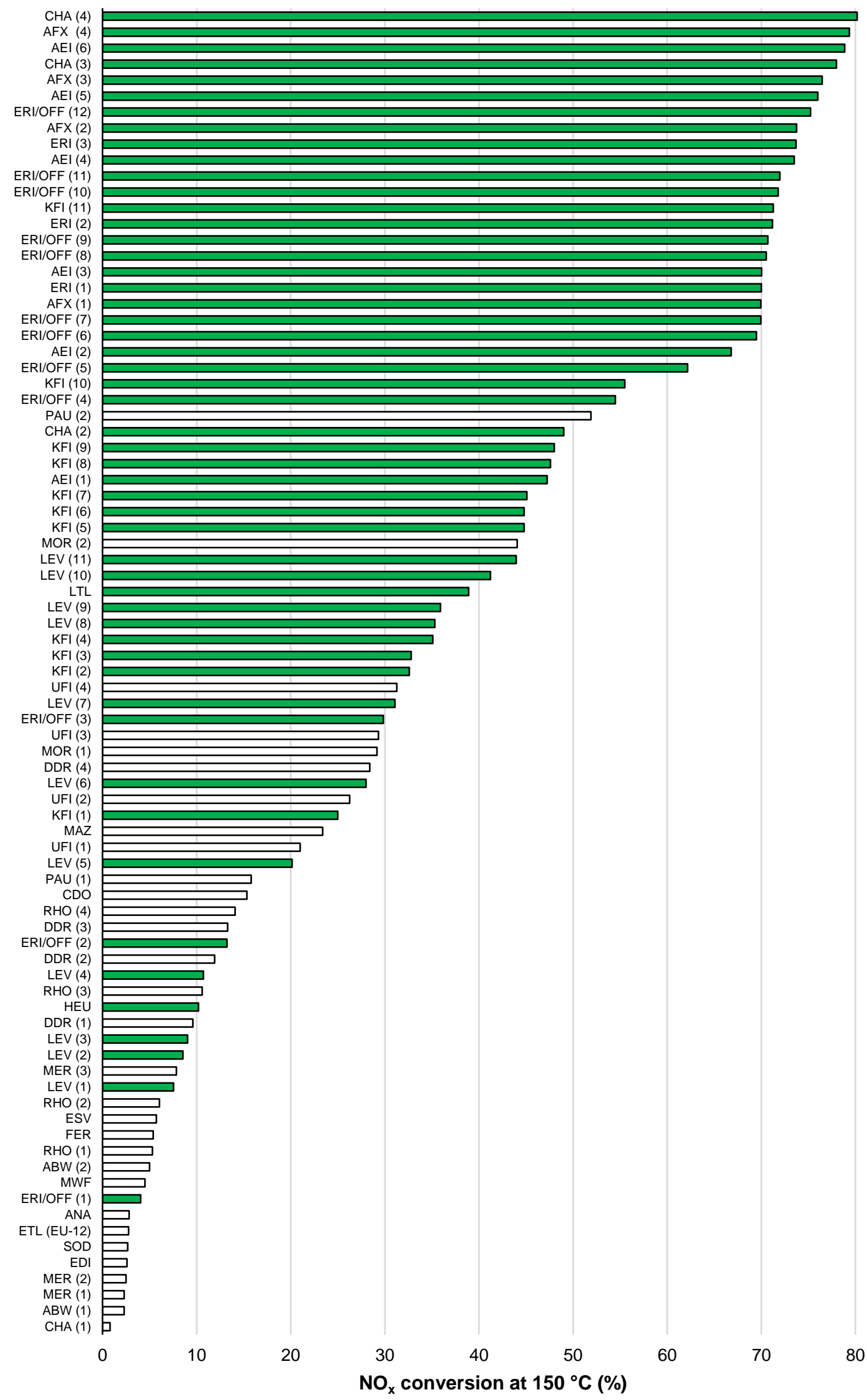

Figure 3: $\mathrm{NO}_{x}$ conversion at $150{ }^{\circ} \mathrm{C}$ on the copper zeolite samples with zeolites having more than $33 \%$ of the T-atoms in d6r building units or more highlighted in green. 


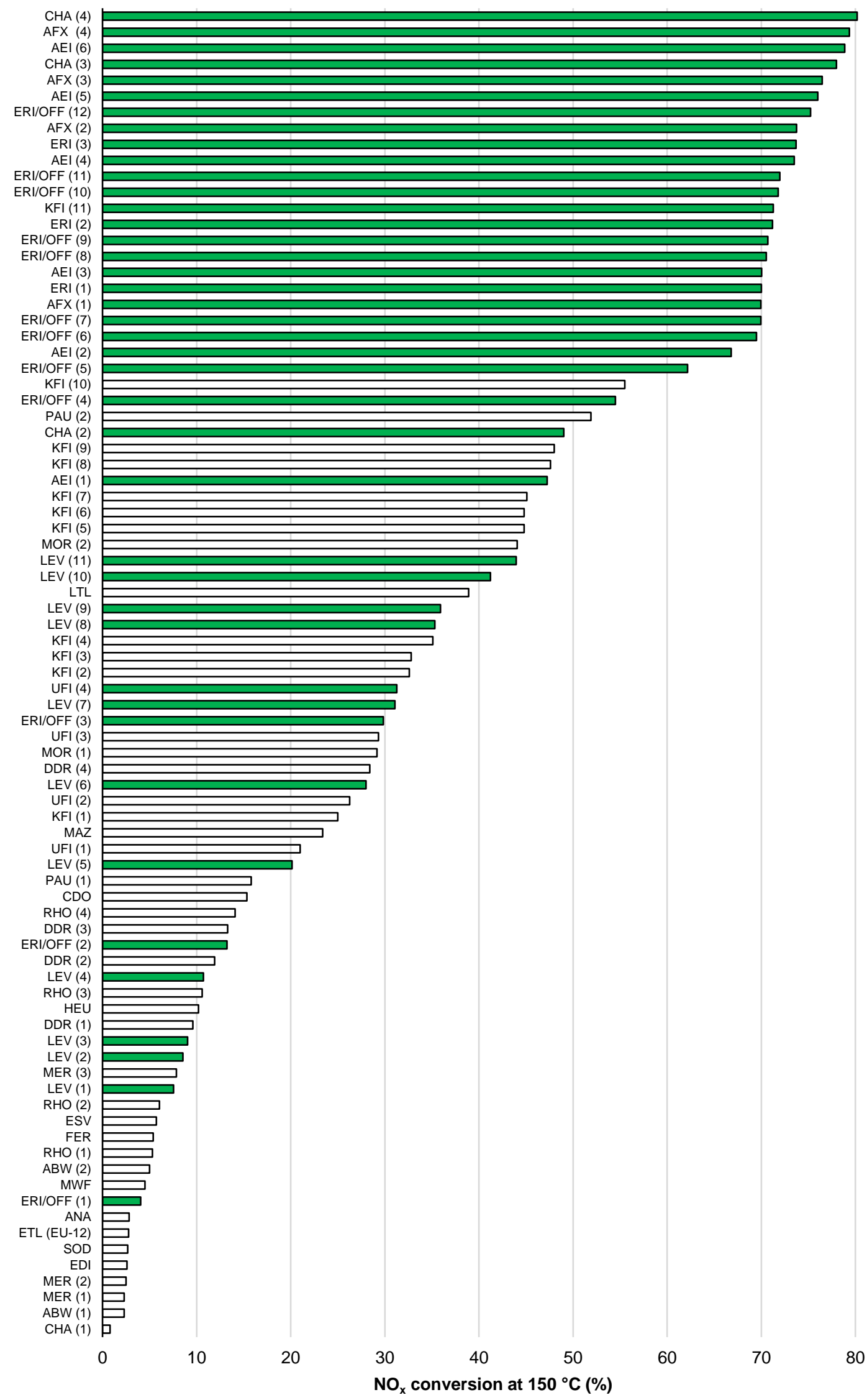

Figure 4: $\mathrm{NO}_{x}$ conversion at $150{ }^{\circ} \mathrm{C}$ on the copper zeolite samples with zeolites more than $33 \%$ of the T-atoms in d6r building units and a framework density larger than or equal to 15.1 T-atoms per $1000 \AA^{3}$ highlighted in green. 


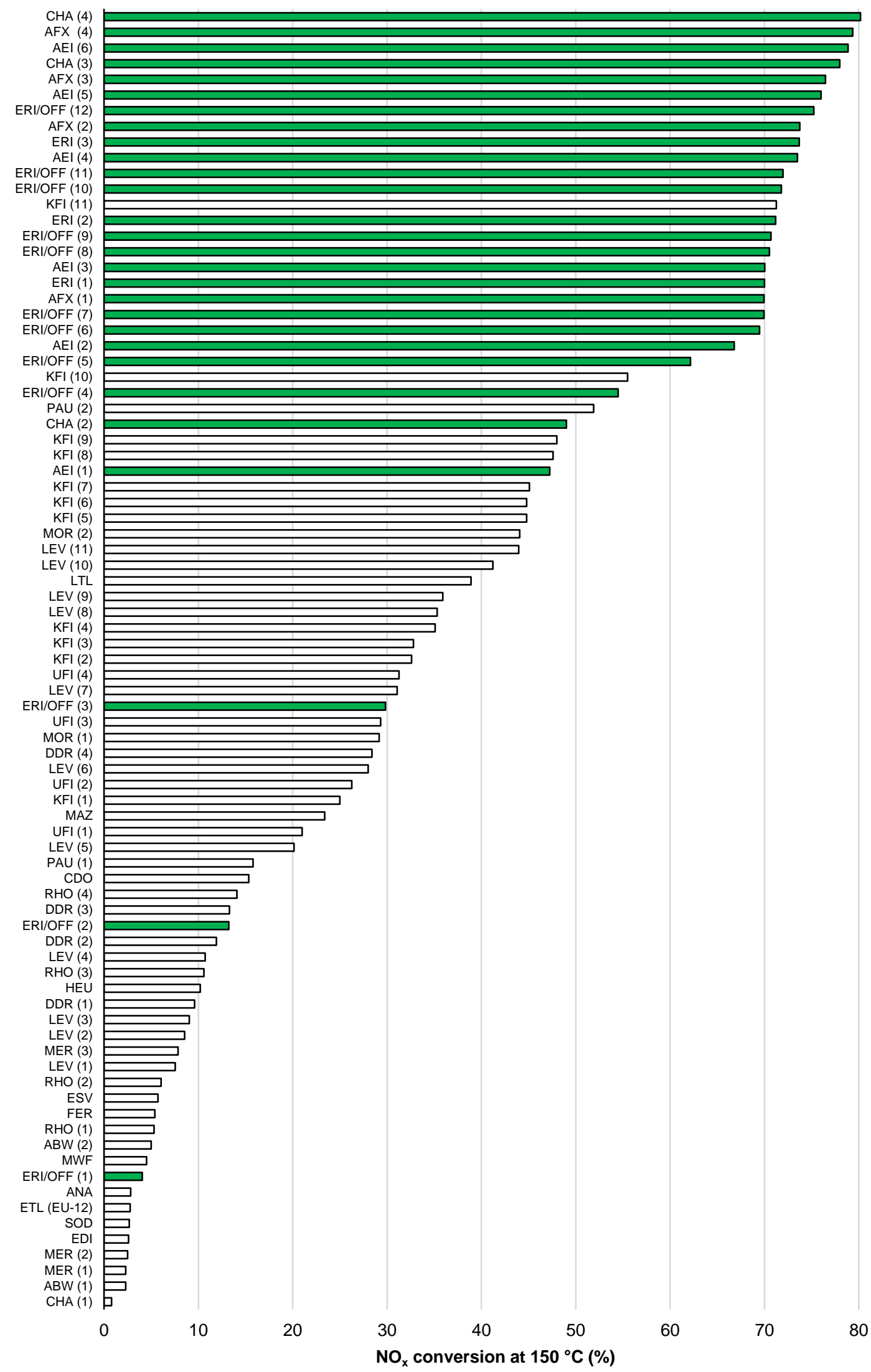

Figure 5: $\mathrm{NO}_{x}$ conversion at $150^{\circ} \mathrm{C}$ on the copper zeolite samples with zeolites having more than $33 \%$ of the T-atoms in d6r building units or more, a framework density larger than or equal to 15.1 T-atoms per $1000 \AA^{3}$ and a 3-dimensional pore system are highlighted in green. 
Zeolites with a high content of double six-rings of framework tetrahedra (d6r), viz. CHA, AFX, AEI, ERI, ERI/OFF, LEV, and KFI showed the highest $\mathrm{NO}_{x}$ conversions (Figure 2). PAU zeolite, which has no d6r building units, was an exception. In literature, d6r structural units in the zeolite have been shown to be the locus of favorable coordination of $\mathrm{Cu}^{2+}$ cations catalyzing the $\mathrm{NH}_{3}-\mathrm{SCR}$ reaction[16,26]. This family of active $\mathrm{NH}_{3}-\mathrm{SCR}$ catalysts has more than $33 \%$ of their T-atoms in d6r building units. There is, however, no direct correlation between the activity and higher number of d6r.

In the dataset the following zeolite types having 33\% or less of their T-atoms in a d6r building unit were catalytically less active (Figure 3): ANA, CDO, DDR, ESV, ETL, FER, HEU, LTL, MAZ, MER, MOR, MWF, PAU, RHO, SOD and UFI. Including compositional variation, this amounts to 25 zeolite samples in total.

The dataset comprised 53 zeolite samples having a Si/Al ratio of at least 3.2, and more than 33\% Tatoms in $\mathrm{d} 6 \mathrm{r}$ framework building units. In this smaller collection, a decisive parameter with respect to $\mathrm{NH}_{3}$-SCR activity appeared to be the framework density (Figure 4). KFI zeolites were among the less active zeolite types. Their framework density of 15.0 is lower than the other zeolites. The zeolite types with the lowest framework density among the most active catalysts were AEI and CHA, both with a framework density of 15.1 T-atoms per $1000 \AA^{3}$ (Table 2). The impact of framework density on low temperature $\mathrm{NH}_{3}$-SCR catalysis could be linked to how well the framework can stabilize a copper ion by coordination with the framework oxygen atoms[36].

The dimensionality of the pore system appeared to be a criterion for still finer discrimination. The most active zeolite types (AEI, AFX, CHA, ERI, and ERI/OFF intergrowth) have 3-dimensional pore systems, whereas LEV has a bidimensional pore system. In the data collection, 28 zeolite samples fulfil all four criteria (Figure 5). The three dimensions of the channel system are expected to provide easy access to the active sites inside the zeolite crystals for reacting molecules and facilitate $\mathrm{Cu}^{2+}$ cation exchange in the catalyst preparation. 


\subsection{Screening of the zeolite database for zeolites with the desired criteria}

Table 2: Tested materials and their values for the different criteria. Criteria 1 is the Si/Al criterion mentioned in the text.

\begin{tabular}{|c|c|c|c|c|c|c|c|}
\hline \multirow{2}{*}{$\begin{array}{l}\text { Zeolite } \\
\text { topology }\end{array}$} & \multirow{2}{*}{\begin{tabular}{|c|} 
Criterion \\
2: T-atoms \\
in d6r $(\%)$
\end{tabular}} & \multirow{2}{*}{$\begin{array}{c}\text { Criterion 3: } \\
\text { Framework density } \\
\left(\mathbf{T} \text {-atoms / } \mathbf{n m}^{\mathbf{3}}\right)\end{array}$} & \multirow{2}{*}{$\begin{array}{c}\text { Criterion 4: } \\
\text { Pore } \\
\text { dimensionality }\end{array}$} & \multicolumn{4}{|c|}{$\begin{array}{c}\text { Criterion } \\
\text { met }\end{array}$} \\
\hline & & & & \begin{tabular}{|l|l|}
1 \\
\end{tabular} & 2 & 3 & 4 \\
\hline $\mathrm{CHA}$ & 100 & 15.1 & 3 & $\mathrm{X}$ & $\mathrm{X}$ & $X$ & $X$ \\
\hline AFX & 100 & 15.1 & 3 & $X$ & $X$ & $X$ & $X$ \\
\hline AEI & 100 & 15.1 & 3 & $X$ & $\mathrm{X}$ & $X$ & $X$ \\
\hline ERI/OFF & 67 & 16.1 & 3 & $\mathrm{X}$ & $X$ & $X$ & $X$ \\
\hline ERI & 67 & 16.1 & 3 & $\mathrm{X}$ & $\mathrm{X}$ & $X$ & $X$ \\
\hline KFI & 100 & 15.0 & 3 & $X$ & $X$ & & $\mathrm{X}$ \\
\hline PAU & 0 & 15.9 & 3 & $\mathrm{X}$ & & $X$ & $X$ \\
\hline MOR & 0 & 17.0 & 2 & $X$ & & $X$ & \\
\hline LEV & 67 & 15.9 & 2 & $\mathrm{X}$ & \begin{tabular}{l|l} 
\\
\end{tabular} & $\mathrm{X}$ & \\
\hline LTL & 33 & 16.7 & 3 & $X$ & $\mathrm{X}$ & $X$ & $X$ \\
\hline UFI & 0 & 15.2 & 2 & $\mathrm{X}$ & & $\mathrm{X}$ & \\
\hline DDR & 0 & 17.9 & 2 & $\mathrm{X}$ & & $X$ & \\
\hline MAZ & 0 & 16.7 & 1 & $\mathrm{X}$ & & $X$ & \\
\hline $\mathrm{CDO}$ & 0 & 18.1 & 2 & $\mathrm{X}$ & & $X$ & \\
\hline HEU & 0 & 17.5 & 2 & $\mathrm{X}$ & & $\mathrm{X}$ & \\
\hline MER & 0 & 16.4 & 3 & $\mathrm{X}$ & & $X$ & $X$ \\
\hline RHO & 0 & 14.5 & 3 & $X$ & & & $\mathrm{X}$ \\
\hline ESV & 0 & 17.7 & 1 & $\mathrm{X}$ & & $X$ & \\
\hline FER & 0 & 17.6 & 2 & $\mathrm{X}$ & & $X$ & \\
\hline ABW & 0 & 17.6 & 1 & & & $X$ & \\
\hline MWF & 0 & 16.1 & 3 & $X$ & & $X$ & $X$ \\
\hline ANA & 0 & 19.2 & 3 & $X$ & & $X$ & $X$ \\
\hline ETL & 0 & 18 & 1 & $X$ & & $X$ & \\
\hline SOD & 0 & 16.7 & 0 & $X$ & & $X$ & \\
\hline EDI & 0 & 16.3 & 3 & & & $\mathrm{X}$ & $\mathrm{X}$ \\
\hline
\end{tabular}

The predictive power of the criteria was evaluated by searching in the Atlas of Zeolite Framework Types for zeolite types which were not contained in the investigated zeolite collection. Currently the Atlas contains 248 zeolite framework topologies[31], of which the 32 (listed in Table 3) contain the d6r building unit. Some of these contain a very small percentage of their T-atoms in d6r building units. As the first criterion demanded more than 33\% of T-atoms in d6r units, the selection is narrowed down to 27 topologies. The second criterion, a framework density of at least $15.1 \mathrm{~T} / \mathrm{nm}^{3}$, reduced this number further to 18 topologies. Including the third criterion, a three dimensional channel system, leads to a limited list of framework types, viz. AEI - AFT - AFX - CHA - ERI - GME - MOZ - OFF - SAT SFW - SZR - -WEN. Promising zeolite specimen with these topologies need to have an aluminosilicate composition and a Si/Al ratio equal or higher than 3.2. SWY satisfies all criteria except the framework density. Additionally, SWY is currently only known as a silicoaluminophosphate and thus outside of the scope of this research.

AEI, AFX, CHA and ERI were already contained in the collection, which leaves 7 zeolite topologies that were not included. Framework types AFT and SAT are not available with aluminosilicate 
composition. The development of synthesis recipes leading to aluminosilicate versions of these framework types would be motivated by this prediction. -WEN is a systematically interrupted framework, indicated by the hyphen preceding the three letters. -WEN frameworks currently exist only as a naturally occurring zeolite. The natural zeolite has low $\mathrm{Si} / \mathrm{Al}$ ratio and the presence of mineral and chemical impurities may be problematic for the catalytic activity and hydrothermal stability[37]. SFW has been mentioned in literature as a potential $\mathrm{NH}_{3}$-SCR catalyst[38,39], and this suggestion is supported here based on the analysis of a wide collection of copper exchanged zeolites. SFW is a zeolite that requires a structure directing agent which is difficult to synthesize[38]. No attempt has been made to synthesize OFF material in this work, though recipes are available in literature[40,41]. The three remaining zeolite types meeting all criteria for being active in low temperature $\mathrm{NH}_{3}-\mathrm{SCR}$ are GME, MOZ and SZR. The prediction was verified by synthesizing zeolite samples with these framework topologies, and verifying their $\mathrm{NH}_{3}$-SCR performance.

Table 3: Identification of promising zeolite frameworks for $\mathrm{NH}_{3}$-SCR catalysis based on the structural criteria. Frameworks marked in bold are identified as promising.

\begin{tabular}{|c|c|c|c|}
\hline Framework & $\% \mathrm{~T}$ atoms in $\mathrm{d} 6 \mathrm{r}$ & Framework density & dimensionality \\
\hline AEI & 100 & 15.1 & 3 \\
\hline AFT & 100 & 15.1 & 3 \\
\hline AFX & 100 & 15.1 & 3 \\
\hline CHA & 100 & 15.1 & 3 \\
\hline ERI & 67 & 16.1 & 3 \\
\hline GME & 100 & 15.1 & 3 \\
\hline MOZ & 67 & 17 & 3 \\
\hline OFF & 67 & 16.1 & 3 \\
\hline SAT & 50 & 16.4 & 3 \\
\hline SFW & 100 & 15.1 & 3 \\
\hline SZR & 67 & 17.6 & 3 \\
\hline -WEN & 67 & 16.6 & 3 \\
\hline AFV & 100 & 15.7 & 2 \\
\hline AVE & 50 & 16.5 & 2 \\
\hline AVL & 100 & 15.8 & 2 \\
\hline EAB & 33 & 16 & 2 \\
\hline EMT & 100 & 13.3 & 3 \\
\hline FAU & 100 & 13.3 & 3 \\
\hline JSR & 100 & 12.3 & 3 \\
\hline KFI & 100 & 15 & 3 \\
\hline LEV & 67 & 15.9 & 2 \\
\hline LTL & 33 & 16.7 & 3 \\
\hline LTN & 25 & 17 & 0 \\
\hline MSO & 60 & 17.8 & 0 \\
\hline MWW & 17 & 15.9 & 2 \\
\hline SAS & 100 & 14.9 & 1 \\
\hline SAV & 100 & 14.6 & 3 \\
\hline SBS & 25 & 13.7 & 3 \\
\hline SBT & 50 & 13.7 & 3 \\
\hline SSF & 67 & 16.5 & 2 \\
\hline
\end{tabular}




\begin{tabular}{|c|c|c|c|}
\hline SWY & 67 & 15.07 & 3 \\
\hline TSC & 100 & 13.2 & 3 \\
\hline
\end{tabular}

\subsection{Zeolites identified as potential $\mathrm{NH}_{3}-\mathrm{SCR}$ candidates}

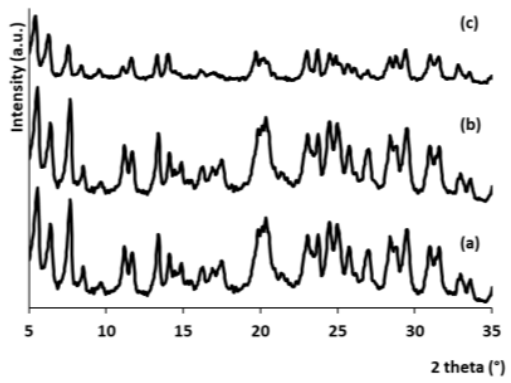

MOZ

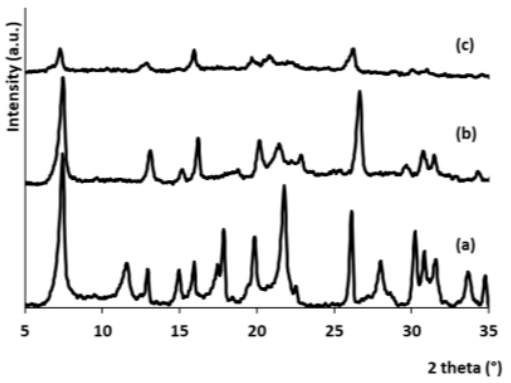

SZR

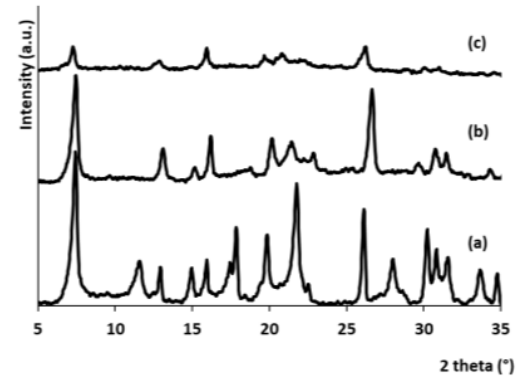

GME

Figure 6: XRD patterns of: MOZ and SZR: (a) calcined, (b) Cu-loaded and (c) hydrothermally treated zeolite; GME (a) as-made, (b) calcined and (c) copper loaded zeolite.

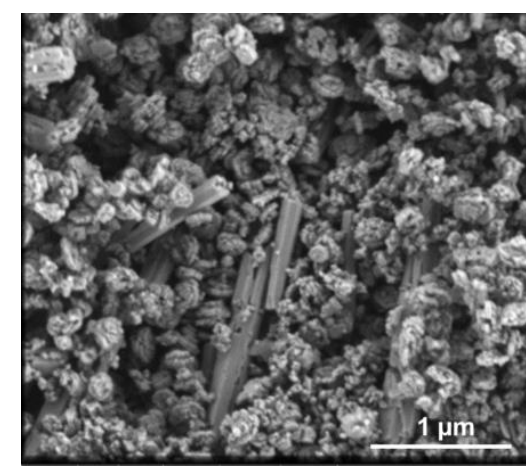

$\mathrm{MOZ}$

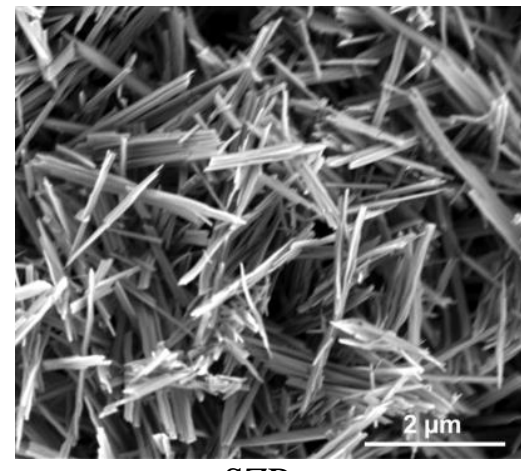

SZR

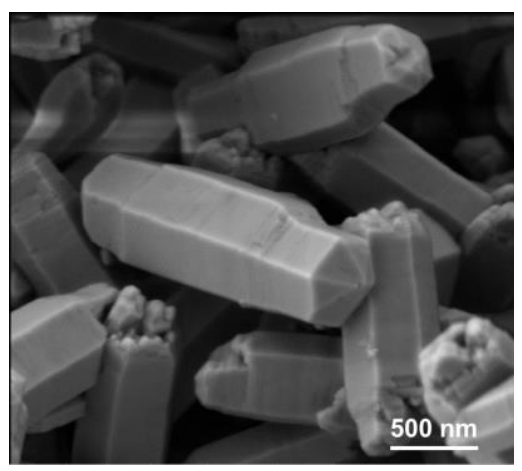

GME

Figure 7: SEM images of MOZ, SZR and GME.

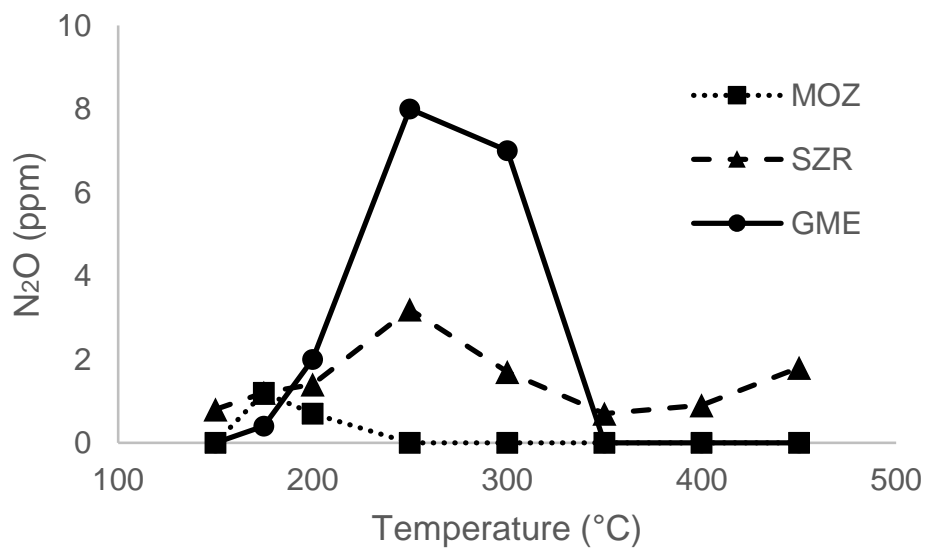

Figure 8: $\mathrm{N}_{2} \mathrm{O}$ formation on MOZ, SZR and GME. 


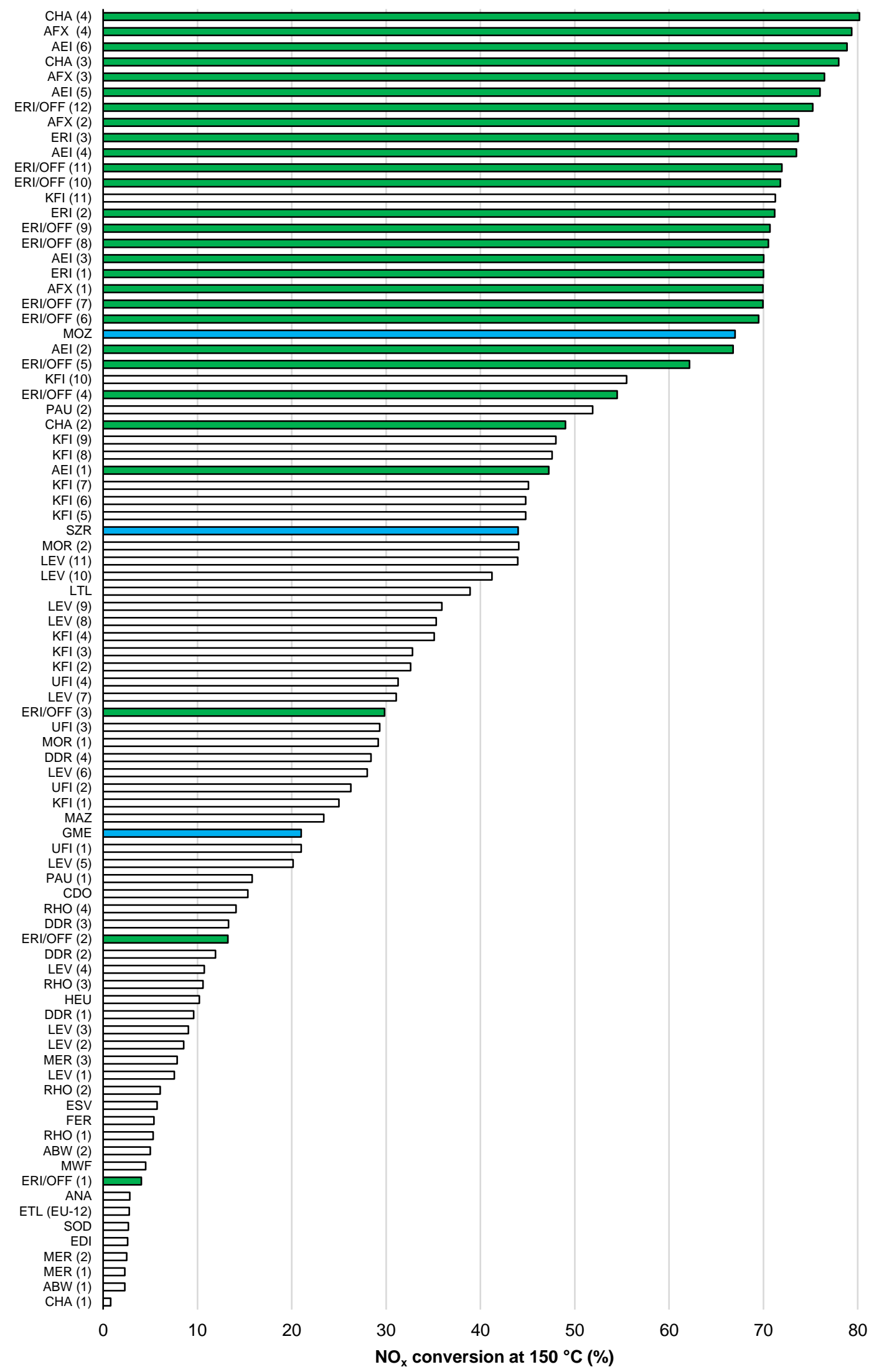

Figure 9: $N O_{x}$ conversion at $150^{\circ} \mathrm{C}$ on Cu-loaded MOZ, SZR and GME compared to the copper zeolite samples. MOZ, SZR and GME are highlighted in blue. Zeolites having more than $33 \%$ of the T-atoms in d6r building units or more, a framework density larger than or equal to 15.1 T-atoms per $1000 \AA^{3}$ and a 3-dimensional pore system are highlighted in green. 


\subsubsection{MOZ zeolite}

The synthesized MOZ zeolite was almost phase pure according to XRD (Figure 6). Traces of an OFF impurity were detected in the XRD pattern and also visualized with SEM (Figure 7). The small submicron particles are identified as having the MOZ framework, whereas the large, thick needles are characteristic of the OFF zeolite. The synthesized zeolite had a Si/Al ratio of 3.6, which is above the threshold value of 3.2 needed for stability reasons. After $\mathrm{NH}_{4}$-exchange and $\mathrm{Cu}$-loading, the zeolite had a residual $\mathrm{K}$ content of $3 \mathrm{wt} \%$ and a $\mathrm{Cu}$ content of $2.6 \mathrm{wt} \%$. The catalytic evaluation is presented in Figure 10. The zeolite showed an excellent $60 \% \mathrm{NO}_{\mathrm{x}}$ conversion at $150{ }^{\circ} \mathrm{C}$ and overall high $\mathrm{NO}_{\mathrm{x}}$ conversion over the investigated temperature range. The catalyst did not form any $\mathrm{N}_{2} \mathrm{O}$ over the entire tested temperature range (Figure 8). In literature $\mathrm{MOZ}$ zeolites are not documented for $\mathrm{NH}_{3}-\mathrm{SCR}$ catalysis. The structural criteria derived from the database analysis lead to the discovery of its potential (Figure 9).

The Cu-exchanged MOZ zeolite sample was hydrothermal aged at $750{ }^{\circ} \mathrm{C}$. The zeolite remained crystalline (Figure 6). And performed as well as the fresh sample in $\mathrm{NH}_{3}-\mathrm{SCR}$ catalysis (Figure 10). At higher temperatures the $\mathrm{NO}_{\mathrm{x}}$ conversion was a bit lower. The return to $150{ }^{\circ} \mathrm{C}$ after the temperature cycle did not show any alteration of the performance, confirming the stability of the zeolite when performing $\mathrm{NH}_{3}-\mathrm{SCR}$.

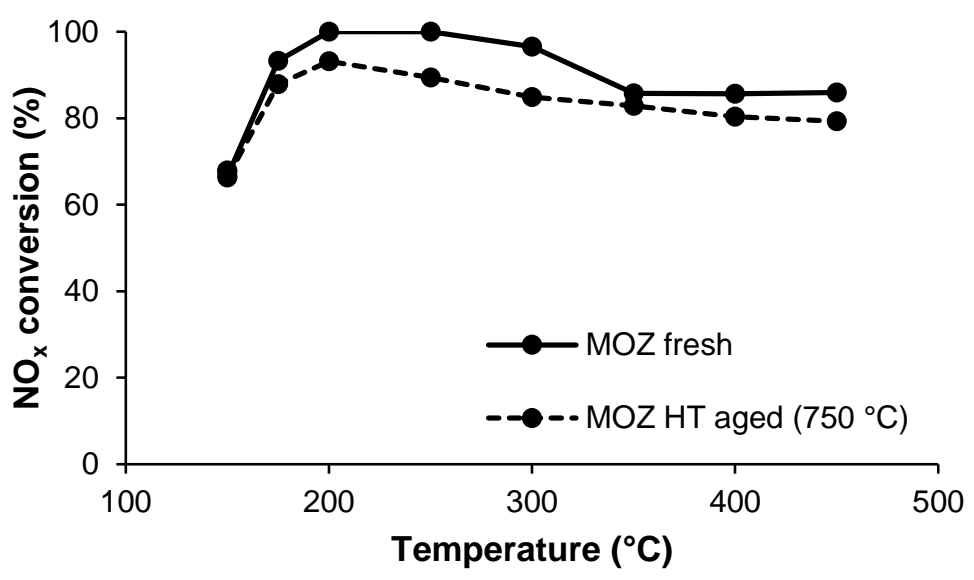

Figure 10: $\mathrm{NO}_{x}$ conversion on $\mathrm{MOZ}$ zeolite in fresh state and after hydrothermal aging in the catalytic screening protocol.

\subsubsection{SZR zeolite}

The SZR zeolite sample was phase pure according to XRD (Figure 6). The sample had a Si/Al ratio of 7.0. After $\mathrm{NH}_{4}$-exchange and $\mathrm{Cu}$-loading, the $\mathrm{Cu}$ content was $3.5 \mathrm{wt} \%$. SEM images (Figure 7) reveal an elongated crystal morphology with individual particles measuring $2-4 \mu \mathrm{m}$ in length and ca. $100 \mathrm{~nm}$ in width. This $\mathrm{Cu}$-loaded SZR zeolite proved to be an active $\mathrm{NH}_{3}$-SCR catalyst (Figure 9 and Figure 11), with minor $\mathrm{N}_{2} \mathrm{O}$ formation between 200 and $300{ }^{\circ} \mathrm{C}$ (Figure 8). At $150{ }^{\circ} \mathrm{C}$, the $\mathrm{NO}_{\mathrm{x}}$ conversion reached $44 \%$, and the conversion rose to over $80 \%$ in the temperature window of $175-300{ }^{\circ} \mathrm{C}$. At higher temperatures, the $\mathrm{NO}_{\mathrm{x}}$ conversion decreased slightly. The return to $150{ }^{\circ} \mathrm{C}$ after the temperature cycle revealed a slight increase of catalytic activity. The SZR catalyst remained crystalline throughout the hydrothermal treatment at $750{ }^{\circ} \mathrm{C}$ (Figure 6). The hydrothermally treated catalyst was less active than the fresh catalyst. Structural damage does not offer an explanation. Segregation of copper from the zeolite pores and clustering are possible explanations for this activity loss[42]. 


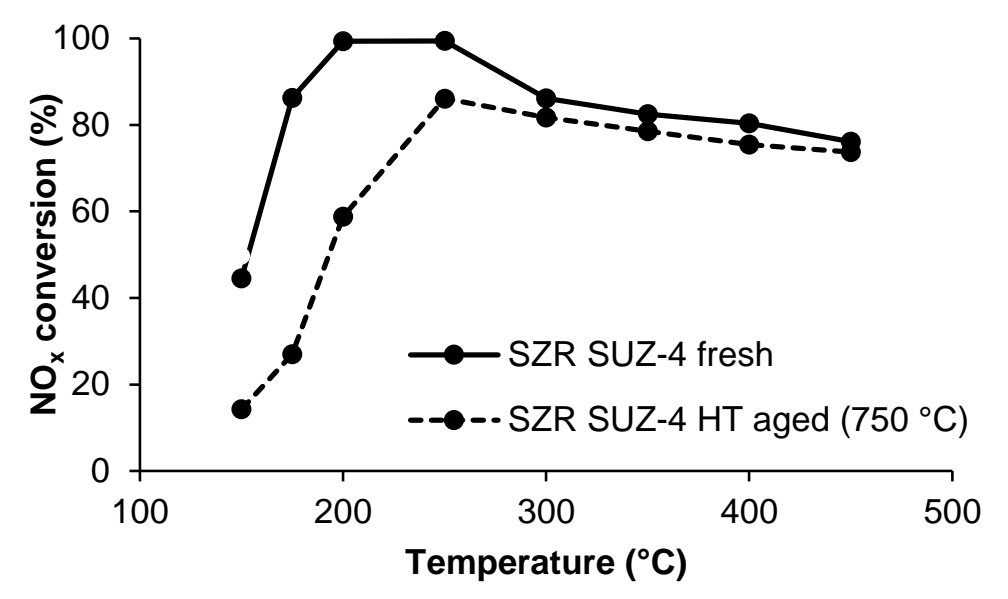

Figure 11: $N O_{x}$ conversion on SZR zeolite in fresh state and after hydrothermal aging in the catalytic screening protocol.

\subsubsection{GME zeolite}

The GME zeolite synthesis resulted in a GME zeolite with some impurity of ANA zeolite (Figure 6). The sample had a $\mathrm{Si} / \mathrm{Al}$ of 5.9, which is higher than any earlier reported value for synthetic GME zeolite[20]. As ANA is a zeolite that only occurs with low $\mathrm{Si} / \mathrm{Al}$ ratio[43], it is expected that the impurity only brings down the overall $\mathrm{Si} / \mathrm{Al}$ ratio, and the $\mathrm{Si} / \mathrm{Al}$ ratio of the GME phase itself could even be higher. The impurity could not be seen in the SEM images (Figure 7). The GME zeolite forms short hexagonal tubes. The center of the tubes is thicker than the extremes, which is probably the result of overgrowths. Some particles still have unfinished edges. After $\mathrm{Cu}$-loading, the $\mathrm{Cu}$ content was $2.0 \mathrm{wt} \%$. The $\mathrm{NO}_{\mathrm{x}}$ conversion over the GME catalyst was limited over the whole temperature range (Figure 12). At $150{ }^{\circ} \mathrm{C}$, a $\mathrm{NO}_{\mathrm{x}}$ conversion of ca. $20 \%$ was reached (Figure 9 and Figure 12). In the $200-300{ }^{\circ} \mathrm{C}$ temperature range, $\mathrm{N}_{2} \mathrm{O}$ was also formed (Figure 8). The reason for this limited activity and selectivity is the zeolite's modest hydrothermal stability, revealed by the XRD pattern of the used catalyst (Figure 6). During the pretreatment step of the reaction protocol, the GME zeolite partially collapses.

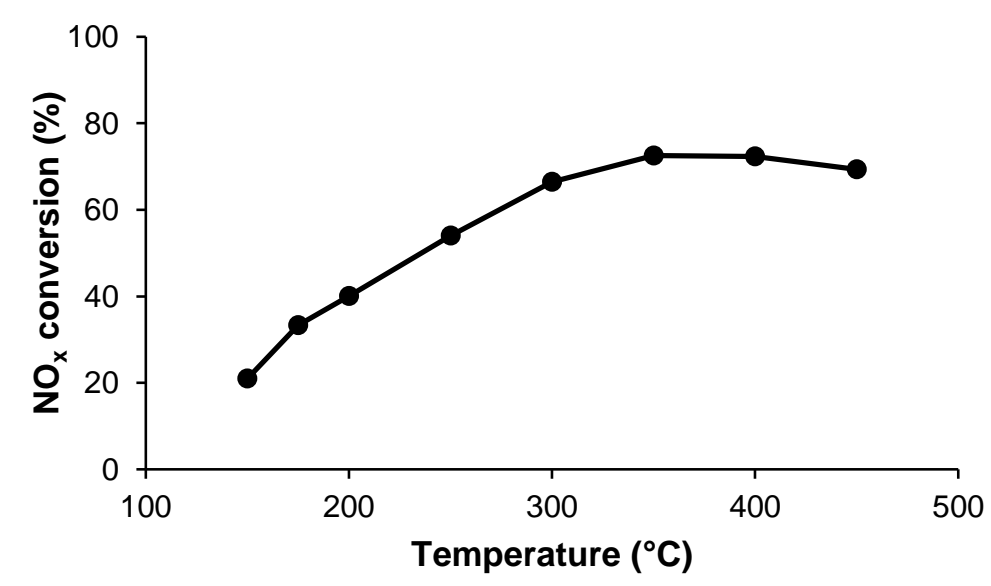

Figure 12: $N O_{x}$ conversion on GME zeolite in fresh state in the catalytic screening protocol. 


\section{Conclusions}

In this work a large dataset of copper exchanged zeolite $\mathrm{NH}_{3}$-SCR catalysts is presented. It allowed to identify which compositional and structural parameters play a key role in the activity of zeolite catalysts in $\mathrm{NH}_{3}$-SCR. Si/Al ratio, the content of double six rings (d6r), framework density and framework dimensionality were identified as critical parameters determining the activity of $\mathrm{NH}_{3}-\mathrm{SCR}$ catalysts at low reaction temperature $\left(150^{\circ} \mathrm{C}\right)$. Copper loaded zeolite materials with a Si/Al ratio higher than 3.2, with more than $33 \%$ of their T-atoms in d6r units, having a framework density of at least $15.1 \mathrm{~T}$-atoms per cubic nanometer and a 3-dimensional framework are most promising candidates for $\mathrm{NH}_{3}$-SCR at low temperature. Eleven currently known zeolites match these criteria: AEI - AFT - AFX - CHA ERI - GME - MOZ - OFF - SFW - SZR - -WEN. Of these, four were used to determine the influence of the compositional and structural parameters, viz. AEI, AFX, CHA and ERI. Three zeolites that are little, if not, documented in $\mathrm{NH}_{3}$-SCR literature were synthesized and catalytically evaluated: GME, $\mathrm{MOZ}$ and SZR. SZR was known in literature as an active $\mathrm{NH}_{3}$-SCR catalyst, but MOZ and GME zeolite have not been tested before for their performance in $\mathrm{NH}_{3}-\mathrm{SCR}$. The MOZ zeolite showed excellent low temperature catalytic performance and resisted hydrothermal treatment at $750{ }^{\circ} \mathrm{C}$. Moreover, the $\mathrm{MOZ}$ zeolite sample contained a high amount of residual potassium from the synthesis, and a limited $\mathrm{Cu}-$ content suggesting that there is room for improvement of the composition to further enhance the catalytic activity. The SZR zeolite was somewhat less active than MOZ, but also here enhancing the $\mathrm{Cu}$ content might lift the $\mathrm{NO}_{\mathrm{x}}$ conversion. The GME zeolite suffers from limited stability, and although it fits with the prediction, it did not survive the testing protocol. This work paves the way to further discoveries of zeolite candidates for $\mathrm{NH}_{3}$-SCR catalysis. Whenever new zeolite structure types become available, the criteria enable to identify potential candidates for the $\mathrm{NH}_{3}-\mathrm{SCR}$ reaction. 


\section{Acknowledgements}

A.H. acknowledges VLAIO for a Baekeland research grant. J.A.M. acknowledge the Flemish Government for long-term structural funding (Methusalem).

\section{References}

[1] LMC Automotive, lmc-auto.com, https://lmc-auto.com (accessed April 16, 2018).

[2] J.A. Sullivan, J. Cunningham, M.A. Morris, K. Keneavey, Conditions in which Cu-ZSM-5 outperforms supported vanadia catalysts in SCR of NOxby NH3, Appl. Catal. B, Environ. 7 (1995) 137-151. doi:10.1016/0926-3373(95)00031-3.

[3] D.W. Fickel, E. D'Addio, J.A. Lauterbach, R.F. Lobo, The ammonia selective catalytic reduction activity of copper-exchanged small-pore zeolites, Appl. Catal. B Environ. 102 (2011) 441-448. doi:10.1016/j.apcatb.2010.12.022.

[4] M. Iwamoto, H. Furukawa, Y. Mine, F. Uemura, S. Mikuriya, S. Kagawa, Copper(II) ionexchanged ZSM-5 zeolites as highly active catalysts for direct and continuous decomposition of nitrogen monoxide, J. Chem. Soc. Chem. Commun. 0 (1986) 1272-1273. doi:10.1039/c39860001272.

[5] A.M. Frey, S. Mert, J. Due-Hansen, R. Fehrmann, C.H. Christensen, Fe-BEA zeolite catalysts for NH3-SCR of NOx, Catal. Letters. 130 (2009) 1-8. doi:10.1007/s10562-009-9894-1.

[6] S. Kieger, G. Delahay, B. Coq, B. Neveu, Selective catalytic reduction of nitric oxide by ammonia over Cu-FAU catalysts in oxygen-rich atmosphere, J. Catal. 183 (1999) 267-280. doi:10.1006/jcat.1999.2398.

[7] J.H. Kwak, R.G. Tonkyn, D.H. Kim, J. Szanyi, C.H.F. Peden, Excellent activity and selectivity of Cu-SSZ-13 in the selective catalytic reduction of NOx with NH3, J. Catal. 275 (2010) 187190. doi:10.1016/j.jcat.2010.07.031.

[8] M. Moliner, C. Franch, E. Palomares, M. Grill, A. Corma, Cu-SSZ-39, an active and hydrothermally stable catalyst for the selective catalytic reduction of NOx, Chem. Commun. 48 (2012) 8264-8266. doi:10.1039/c2cc33992g.

[9] M. De Prins, E. Verheyen, S. Kerkhofs, A. Hoffmann, G. Vanbutsele, S.P. Sree, S. Radhakrishnan, L. Van Tendeloo, E. Breynaert, C.E.A. Kirschhock, F.-W. Schütze, J.A. Martens, EU-7 zeolite: a synthetic BIK type zeolite with high hydrothermal stability, Chem. Commun. 54 (2018) 5626-5629. doi:10.1039/C8CC02227E.

[10] F. Gao, Y. Wang, N.M. Washton, M. Kollár, J. Szanyi, C.H.F. Peden, Effects of alkali and alkaline earth cocations on the activity and hydrothermal stability of Cu/SSZ-13 NH3-SCR catalysts, ACS Catal. 5 (2015) 6780-6791. doi:10.1021/acscatal.5b01621.

[11] U. Deka, I. Lezcano-Gonzalez, B.M. Weckhuysen, A.M. Beale, Local environment and nature of $\mathrm{Cu}$ active sites in zeolite-based catalysts for the selective catalytic reduction of NOx, Acs Catal. 3 (2013) 413-427. doi:10.1021/Cs300794s.

[12] U. Deka, A. Juhin, E.A. Eilertsen, H. Emerich, M.A. Green, S.T. Korhonen, B.M. Weckhuysen, A.M. Beale, Confirmation of isolated $\mathrm{Cu} 2+$ ions in SSZ-13 zeolite as active sites in NH 3selective catalytic reduction, J. Phys. Chem. C. (2012). doi:10.1021/jp212450d.

[13] Y. Shan, W. Shan, X. Shi, J. Du, Y. Yu, H. He, A comparative study of the activity and hydrothermal stability of Al-rich Cu-SSZ-39 and Cu-SSZ-13, Appl. Catal. B Environ. 264 
(2020). doi:10.1016/j.apcatb.2019.118511.

[14] S.J. Gentry, N.W. Hurst, A. Jones, Temperature programmed reduction of copper ions in zeolites, J. Chem. Soc. Faraday Trans. 1 Phys. Chem. Condens. Phases. 75 (1979) 1688-1699. doi:10.1039/F19797501688.

[15] G. Turnes Palomino, S. Bordiga, A. Zecchina, G.L. Marra, C. Lamberti, XRD, XAS, and IR characterization of copper-exchanged Y zeolite, J. Phys. Chem. B. 104 (2000) 8641-8651. doi:10.1021/jp000584r.

[16] H. Wang, R. Xu, Y. Jin, R. Zhang, Zeolite structure effects on $\mathrm{Cu}$ active center, SCR performance and stability of Cu-zeolite catalysts, Catal. Today. 327 (2019) 295-307. doi:10.1016/j.cattod.2018.04.035.

[17] S. Mohan, P. Dinesha, S. Kumar, NOx reduction behaviour in copper zeolite catalysts for ammonia SCR systems: A review, Chem. Eng. J. 384 (2020) 123253. doi:10.1016/j.cej.2019.123253.

[18] M. De Prins, J.A. Martens, E.J.J. Verheyen, S.J.P. Kerkhofs, S.P. Sree, F.-W. Schütze, Copper containing MOZ zeolite for selective NOx reduction catalysis, EP3363540, 2018.

[19] M.A. Asensi, M.A. Camblor, A. Martínez, Zeolite SUZ-4: Reproducible synthesis, physicochemical characterization and catalytic evaluation for the skeletal isomerization of $\mathrm{n}$ butenes, Microporous Mesoporous Mater. 28 (1999) 427-436. doi:10.1016/S13871811(98)00314-X.

[20] M. Dusselier, J.H. Kang, D. Xie, M.E. Davis, CIT-9: A fault-free gmelinite zeolite, Angew. Chemie - Int. Ed. 56 (2017) 13475-13478. doi:10.1002/anie.201707452.

[21] N. Martín, C.R. Boruntea, M. Moliner, A. Corma, Efficient synthesis of the Cu-SSZ-39 catalyst for deNOx applications, Chem. Commun. 51 (2015) 11030-11033. doi:10.1039/C5CC03200H.

[22] H. Zhu, J.H. Kwak, C.H.F. Peden, J. Szanyi, In situ DRIFTS-MS studies on the oxidation of adsorbed NH3 by NOx over a Cu-SSZ-13 zeolite, Catal. Today. (2013). doi:10.1016/j.cattod.2012.08.043.

[23] K. Leistner, O. Mihai, K. Wijayanti, A. Kumar, K. Kamasamudram, N.W. Currier, A. Yezerets, L. Olsson, Comparison of $\mathrm{Cu} / \mathrm{BEA}, \mathrm{Cu} / \mathrm{SSZ}-13$ and $\mathrm{Cu} / \mathrm{SAPO}-34$ for ammonia-SCR reactions, Catal. Today. 258 (2015) 49-55. doi:10.1016/j.cattod.2015.04.004.

[24] M. Iwasaki, H. Shinjoh, A comparative study of "standard", "fast" and "NO2" SCR reactions over Fe/zeolite catalyst, Appl. Catal. A Gen. (2010). doi:10.1016/j.apcata.2010.09.034.

[25] H. Kubota, C. Liu, T. Toyao, Z. Maeno, M. Ogura, N. Nakazawa, S. Inagaki, Y. Kubota, K. Shimizu, Formation and Reactions of NH 4 NO 3 during Transient and Steady-State NH 3 -SCR of NO x over H-AFX Zeolites: Spectroscopic and Theoretical Studies, ACS Catal. 10 (2020) 2334-2344. doi:10.1021/acscatal.9b05151.

[26] F. Gao, J.H. Kwak, J. Szanyi, C.H.F. Peden, Current understanding of Cu-exchanged chabazite molecular sieves for use as commercial diesel engine deNOx catalysts, Top. Catal. 56 (2013) 1441-1459. doi:10.1007/s11244-013-0145-8.

[27] S.J. Schmieg, S.H. Oh, C.H. Kim, D.B. Brown, J.H. Lee, C.H.F. Peden, D. Heui, D.H. Kim, Thermal durability of Cu-CHA NH 3-SCR catalysts for diesel NO x reduction, Catal. Today. 184 (2012) 252-261. doi:10.1016/j.cattod.2011.10.034.

[28] J. Wang, H. Zhao, G. Haller, Y. Li, Recent advances in the selective catalytic reduction of NOx with NH3 on Cu-chabazite catalysts, Appl. Catal. B Environ. 202 (2017) 346-354. doi:10.1016/j.apcatb.2016.09.024.

[29] T. Ryu, N.H. Ahn, S. Seo, J. Cho, H. Kim, D. Jo, G.T. Park, P.S. Kim, C.H. Kim, E.L. Bruce, 
P.A. Wright, I.S. Nam, S.B. Hong, Fully copper-exchanged high-silica LTA zeolites as unrivaled hydrothermally stable NH3-SCR catalysts, Angew. Chemie - Int. Ed. 56 (2017) 32563260. doi:10.1002/anie.201610547.

[30] H. Chang, X. Qin, L. Ma, T. Zhang, J. Li, Cu/SAPO-34 prepared by a facile ball milling method for enhanced catalytic performance inthe selective catalytic reduction of NOx with NH3, Phys.Chem.Chem.Phys. (2019). doi:10.1039/C9CP04519H.

[31] http://www.iza-online.org, IZA website, (n.d.). http://www.iza-online.org/ (accessed March 2, 2020).

[32] W. Lutz, Zeolite Y: Synthesis, Modification, and Properties-A Case Revisited, Adv. Mater. Sci. Eng. 2014 (2014) 1-20. doi:10.1155/2014/724248.

[33] H. Ghobarkar, O. Schäf, Hydrothermal synthesis and morphology of thomsonite and edingtonite, Cryst. Res. Technol. 32 (1997) 653-657. doi:10.1002/crat.2170320508.

[34] T. Matsumoto, T. Miyazaki, Y. Goto, Synthesis and characterization of Li-type EDI zeolite, J. Eur. Ceram. Soc. 26 (2006) 455-458. doi:10.1016/j.jeurceramsoc.2005.06.003.

[35] R.M. Barrer, E.A.D. White, 283. The hydrothermal chemistry of silicates. Part I. Synthetic lithium aluminosilicates, J. Chem. Soc. (1951) 1267. doi:10.1039/jr9510001267.

[36] C. Paolucci, I. Khurana, A.A. Parekh, S. Li, A.J. Shih, H. Li, J.R. Di Iorio, J.D. AlbarracinCaballero, A. Yezerets, J.T. Miller, W.N. Delgass, F.H. Ribeiro, W.F. Schneider, R. Gounder, Dynamic multinuclear sites formed by mobilized copper ions in NOx selective catalytic reduction, Science (80-. ). 357 (2017) 898-903. doi:10.1126/science.aan5630.

[37] H.-R. Wenk, The structure of wenkite, Z. Krist. 137 (1973) 113-126. doi:10.1524/zkri.1973.137.16.113.

[38] D. Xie, L.B. Mccusker, C. Baerlocher, S.I. Zones, W. Wan, X. Zou, SSZ-52, a zeolite with an 18-layer aluminosilicate framework structure related to that of the deNOx catalyst Cu-SSZ-13, J. Am. Chem. Soc. 135 (2013) 10519-10524. doi:10.1021/ja4043615.

[39] T.M. Davis, A.T. Liu, C.M. Lew, D. Xie, A.I. Benin, S. Elomari, S.I. Zones, M.W. Deem, Computationally guided synthesis of SSZ-52: a zeolite for engine exhaust clean-up, Chem. Mater. 28 (2016) 708-711. doi:10.1021/acs.chemmater.5b04578.

[40] H. Robson, K.P. Lillerud, Verified syntheses of zeolitic materials, 2001. doi:10.1016/B978044450703-7/50184-8.

[41] A. Matijasic, J. Patarin, Synthesis of OFF-type zeolite in a quasi non aqueous medium: Structure directing role of p-dioxane and alkaline cations, Microporous Mesoporous Mater. (1999). doi:10.1016/S1387-1811(99)00009-8.

[42] J.H. Kwak, D. Tran, S.D. Burton, J. Szanyi, J.H. Lee, C.H.F. Peden, Effects of hydrothermal aging on NH3-SCR reaction over Cu/zeolites, J. Catal. 287 (2012) 203-209. doi:10.1016/j.jcat.2011.12.025.

[43] Y. Wang, X. Li, Z. Xue, L. Dai, S. Xie, Q. Li, Preparation of zeolite ANA crystal from zeolite Y by in situ solid phase iso-structure transformation, J. Phys. Chem. B. 114 (2010) 5747-5754. doi:10.1021/jp907706c. 